(c) American Dairy Science Association, 2006.

\title{
Plasma Leptin Concentrations Correlate with Luteinizing Hormone Secretion in Early Postpartum Holstein Cows
}

\author{
H. Kadokawa, ${ }^{* 1}$ D. Blache, $†$ and G. B. Martin $†$ \\ *Department of Animal Breeding and Reproduction, National Institute of Livestock \& Grassland Science, Senbonmatsu 768, \\ Nasushiobara, Tochigi 329-2793, Japan \\ †School of Animal Biology, Faculty of Natural and Agricultural Sciences, The University of Western Australia, Crawley 6009, Australia
}

\begin{abstract}
We tested the hypothesis that hypothalamic-pituitary activity, bioassayed by LH pulse frequency, in dairy cattle during early lactation is related to measures of energy status and to circulating profiles of free fatty acids (FFA), insulin, insulin-like growth factor-I (IGF-I), leptin, and growth hormone (GH). On d 14 postpartum, before first ovulation and during the period of negative energy balance $(-23.4 \pm 2.4 \mathrm{Mcal} / \mathrm{d}$ of metabolizable energy), blood plasma was sampled from 18 multiparous cows at 10-min intervals for $8 \mathrm{~h}$. All samples were assayed for $\mathrm{LH}$ and $\mathrm{GH}$ and hourly samples were assayed for FFA, insulin, IGF-I, and leptin. Milk yield and composition, body condition score, and energy balance were also measured. Frequency of LH pulses was correlated positively with energy balance $(\mathrm{r}=0.51)$ and plasma leptin concentrations $(\mathrm{r}=0.73)$, and negatively with milk fat content $(\mathrm{r}=-0.52)$. Amplitude of the LH pulses was correlated only with leptin $(r=0.53)$. Frequency of GH pulses was not correlated with any measure of LH secretion, but was correlated negatively with plasma concentrations of insulin $(r=-0.62)$ and IGF-I $(r=-0.61)$. First ovulation was observed $34 \pm 4$ $\mathrm{d}$ after parturition. These observations reveal an important linkage between pulsatile LH secretion and blood leptin concentrations during the early postpartum period in dairy cows, when their energy balance is negative, and may explain the delay in ovulation.
\end{abstract}

Key words: postpartum anovulation, negative energy balance, growth hormone resistance, negative feedback of insulin-like growth factor-I

\section{INTRODUCTION}

In dairy cows during early lactation, the combination of a high rate of milk secretion with limited feed intake leads to a negative energy balance. In an attempt to meet the high energy demand for lactation, postpartum

Received November 22, 2005.

Accepted March 10, 2006.

${ }^{1}$ Corresponding author: hiroya@yamaguchi-u.ac.jp dairy cows rely on the mobilization of adipose tissue, and they often lose $60 \%$ or more of their body fat in the first few weeks after calving (Tamminga et al., 1997). This rapid mobilization of fat is a major risk factor for prolonged anovulatory periods; the delay from parturition to the beginning of recovery of energy balance is positively correlated with the interval from parturition to first ovulation (Zurek et al., 1995).

Negative energy balance during early lactation is associated with changes in the major metabolic hormones, with reduced plasma concentrations of insulin, IGF-I, and leptin, and increased secretion of growth hormone (GH; Beam and Butler, 1998; Kadokawa et al., 2000; Butler et al., 2003). These hormones are thought to act at hypothalamic, pituitary, and ovarian levels, linking changes in reproductive activity to changes in energy balance. For example, IGF-I is a good predictor of the capacity of energy-restricted cows to resume cyclicity (Roberts et al., 1997), and presence of anovulatory follicles is associated with low plasma concentrations of IGF-I (Beam and Butler, 1998). Insulin and IGF-I stimulate steroidogenesis and proliferation of theca and granulosa cells in vitro (Spicer and Stewart, 1996). Leptin, the concentrations of which decrease during early lactation, is associated with abnormalities in ovarian cyclicity in early postpartum cows (Kadokawa et al., 2000).

The key driver of the resumption of ovulation during the postpartum period is the increase in LH pulse frequency that, in turn, is controlled by an increase in GnRH pulse frequency (Beam and Butler, 1998). There is some indirect evidence suggesting that insulin, IGFI, and leptin are, either individually or in synergy, involved in the stimulation of GnRH-LH secretion during recovery of energy balance (Liefers et al., 2005), but none of these metabolic hormones have been directly linked to the control of the pulsatile secretion of $\mathrm{LH}$ (and thus, GnRH).

We therefore tested the hypothesis that, in dairy cattle during early lactation, the activity of the hypothalamo-pituitary axis, as measured by the LH pulse frequency, would be correlated with the plasma concentrations of insulin, IGF-I, and leptin, and with the 
frequency and amplitude of pulsatile GH secretion. In addition to these metabolic hormones, FFA and milk fat (reflecting the rate of mobilization of fat reserves) and other measures of energy status were measured to test whether they are potential predictors of a suppression of pulsatile GnRH-LH secretion.

\section{MATERIALS AND METHODS}

\section{Cows and Procedures}

All procedures used in this experiment were approved by the Animal Care and Use Committee of National Agricultural Research Center for Hokkaido Region (Sapporo, Japan). Eighteen multiparous Holstein dairy cows (parity $=2.9 \pm 0.3$ ) were housed in a tie-stall barn. Samples of the feed were analyzed to determine the amount to be offered. Cows were provided with free access to their diet during the dry period to meet drycow requirements according to the Japanese Feeding Standard (Agriculture, Forestry and Fisheries Research Council Secretariat, 1999). At calving, no cases of dystocia or retained placenta were observed, and the calves were removed from their dams on $\mathrm{d} 0$ (parturition) or $\mathrm{d} 1$. From the day of calving, cows were offered a daily ration consisting of 25 to $30 \mathrm{~kg}$ of grass silage (30.7\% DM, 2.25 Mcal/kg of ME on a DM basis, and $12.1 \% \mathrm{CP}), 6 \mathrm{~kg}$ of grass hay $(83.1 \% \mathrm{DM}, 1.93 \mathrm{Mcal} / \mathrm{kg}$ of $\mathrm{ME}$, and $6.6 \% \mathrm{CP}), 2 \mathrm{~kg}$ of alfalfa cubes $(89.0 \% \mathrm{DM}$, $2.02 \mathrm{Mcal} / \mathrm{kg}$ of ME, and $17.0 \% \mathrm{CP}), 2 \mathrm{~kg}$ of beet pulp (85.6\% DM, $2.70 \mathrm{Mcal} / \mathrm{kg}$ of ME, and $12.7 \% \mathrm{CP}), 1 \mathrm{~kg}$ of heated soybeans $(93.0 \% \mathrm{DM}, 3.85 \mathrm{Mcal} / \mathrm{kg}$ of $\mathrm{ME}$, and $43.0 \% \mathrm{CP})$, and concentrate $(86.5 \% \mathrm{DM}, 3.10 \mathrm{Mcal} /$ $\mathrm{kg}$ of $\mathrm{ME}$, and $21.2 \% \mathrm{CP}$ ). Amount of concentrate fed was $3 \mathrm{~kg} / \mathrm{d}$ on $\mathrm{d} 0$ and was increased at the rate of $1 \mathrm{~kg} / \mathrm{d}$ for $6 \mathrm{~d}$ after calving. Subsequent amounts of concentrate and grass silage were determined according to the Japanese Feeding Standard. The daily ration was divided between 2 feeding times: $0900 \mathrm{~h}$, immediately after removal of the remaining feed, and at $1600 \mathrm{~h}$. Water and mineral blocks (Koen-S, Nippon Zenyaku Kogyo, Co., Ltd., Fukushima, Japan) were provided ad libitum. Cows were milked twice daily, at 0840 and $1900 \mathrm{~h}$, and were allowed to exercise in a paddock from about 1030 to $1600 \mathrm{~h}$ every day, except on d 14 (the day of the study).

On d 13, all cows were fitted with an indwelling jugular catheter (Medikit Catheter Kit 16G, Medikit, Tokyo, Japan) connected to an extension tube (LX1-L100; Top, Tokyo, Japan), and 3-way control valve (Terumo, Tokyo, Japan) attached to the back between the shoulders. This sampling methodology had previously been confirmed not to reduce feed intake. On d 14, blood was sampled at 10-min intervals from 1000 to $1800 \mathrm{~h}$. Samples were centrifuged at $12,000 \times g$ for $30 \mathrm{~min}$ at $4^{\circ} \mathrm{C}$, and plasma was harvested and stored at $-35^{\circ} \mathrm{C}$ until analysis. These serial samples were used for analysis of LH and GH. Hourly samples were collected by subsampling every sixth plasma sample for the analysis of hormones and metabolites other than LH and GH. Body condition scores on a 5-point scale (Edmonson et al., 1989) were recorded by the same person on $\mathrm{d} 14$. Body weight ( $676 \pm 16 \mathrm{~kg})$, milk yield $(40.6 \pm 1.8 \mathrm{~kg})$, and milk fat content $(4.24 \pm 0.17 \%)$ were recorded for each cow on $\mathrm{d} 14$. To calculate energy balance based on the Japanese Feeding Standard, amounts of feed offered and refused were weighed for each cow on the mornings of d 14 and 15. Energy balance was the difference between the ME intake and the ME requirement, which was the sum of the ME requirements for maintenance $(0.1163 \times$ metabolic $\mathrm{BW})$ and for lactation, based on the equation: $(0.0913 \times$ milk fat content +0.3678$) \times$ milk yield $\times 1.613$.

Absence of postpartum ovulation before and immediately after the frequent blood sampling, and intervals to first postpartum ovulation, were verified by daily rectal palpation and by 4-times weekly ultrasound using a real-time linear array ultrasound scanner (SSD620; Aloka, Tokyo, Japan) equipped with a 5-MHz rectal probe (UST-580U-5; Aloka), beginning on d 6 to 8 postpartum and continuing until the second postpartum ovulation. Sizes of the largest follicles in the ovaries of all cows also were measured using ultrasound before the last blood sample was collected on d 14. Jugular blood was sampled 4 times per week from d 0 to about d 80. First ovulations detected by rectal palpation and ultrasound were confirmed by the first postpartum rise in progesterone $(>1 \mathrm{ng} / \mathrm{mL}$ ) in 2 consecutive samples ( $3 \mathrm{~d}$ were subtracted from the time of the initial rise to calculate the day of first ovulation; Canfield and Butler, 1991).

\section{Assays}

Plasma LH was assayed in duplicate by double-antibody radioimmunoassay (RIA) using ${ }^{125}$ I-labeled bovine LH (bLH) and anti-oLH-antiserum [AFP11743B and AFP192279, National Hormone and Pituitary Program of the National Institute of Diabetes and Digestive and Kidney Diseases (NIDDK), Los Angeles, CA]. Limit of detection was $0.40 \mathrm{ng} / \mathrm{mL}$ and the intra- and interassay coefficients of variation were 3.9 and $6.9 \%$, respectively, at $0.51 \mathrm{ng} / \mathrm{mL}$.

Plasma GH was measured in duplicate using a double-antibody RIA kit from NIDDK comprising antiserum NIDDK-anti-oGH-2 and standards NIDDK-oGHI-5. Limit of detection was $0.50 \mathrm{ng} / \mathrm{mL}$ and the intraand interassay coefficients of variation were 5.8 and $8.5 \%$, respectively, at $2.12 \mathrm{ng} / \mathrm{mL}$. 
Leptin was measured using the specific RIA based on recombinant bovine leptin in the assay system described in detail by Blache et al. (2000). All samples were processed in duplicate in a single assay with a limit of detection of $0.07 \mathrm{ng} / \mathrm{mL}$ and an intraassay coefficient of variation of $5.8 \%$ at $0.42 \mathrm{ng} / \mathrm{mL}$.

Plasma concentration of FFA was measured with an autoanalyzer (model-7170; Hitachi Co. Ltd., Tokyo, Japan) and commercial kits (Kainos Laboratories, Inc., Tokyo, Japan). All samples were processed in a single assay with an intraassay coefficient of variation of less than $1.0 \%$ at $38 \mathrm{nEq} / \mathrm{mL}$.

Plasma insulin was assayed in duplicate with a commercial RIA kit (Insulin-Eiken; Eiken Chemical Co Ltd., Tokyo, Japan). All samples were processed in a single assay with a limit of detection of $500 \mathrm{nU} / \mathrm{mL}$ and an intraassay coefficient of variation of $5.8 \%$ at 860 $\mathrm{nU} / \mathrm{mL}$.

Plasma IGF-I was assayed in duplicate by doubleantibody RIA with human recombinant IGF-I (ARM4050; Amersham-Pharmacia Biotech, Buckinghamshire, UK) and anti-human IGF-I antiserum (AFP4892898; National Hormone and Pituitary Program of the NIDDK) following acid and ethanol extraction and cryoprecipitation. All samples were processed in a single assay with a limit of detection of $0.51 \mathrm{ng} /$ $\mathrm{mL}$ and an intraassay coefficient of variation of $6.6 \%$ at $14.6 \mathrm{ng} / \mathrm{mL}$.

Plasma progesterone was assayed in duplicate by double-antibody RIA using ${ }^{3} \mathrm{H}$-progesterone (New England Nuclear, Boston, MA) and antiserum to progesterone (donated by N. Takenouchi, National Agricultural Research Center for Tohoku Region, Morioka, Japan). Limit of detection was $7.8 \mathrm{pg} / \mathrm{mL}$ and the intraand interassay coefficients of variation were 3.6 and $7.4 \%$, respectively, at $15.6 \mathrm{pg} / \mathrm{mL}$.

\section{Statistical Analyses}

Number of LH pulses per $8 \mathrm{~h}$, amplitude of $\mathrm{LH}$ pulses, and mean LH concentrations were determined using the Pulsar algorithm (Merriam and Watcher, 1982) in the Munro pulse analysis program (Zaristow Software, West Morham, Haddington, UK). The G-parameters (number of SD by which a peak must exceed the baseline to be accepted) were set at 3.0, 2.1, 1.5, 1.2, and 1.0 for G1 to G5, for pulses composed of 1 to 5 successive samples that exceed the baseline. These same values were used by Canfield and Butler (1991). The Baxter parameters describing parabolic relationship between concentration of a hormone in a sample and the standard deviation (assay variation) about the concentration were 0.147 (b1, the $\mathrm{y}$ intercept), 0.027 (b2, the $\mathrm{x}$ coefficient), and 0.0093 (b3, the $\mathrm{x}^{2}$ coefficient). Mean concentration was calculated using all the values for a profile.

The same procedure was used for the analysis of the GH profiles. The G-parameters were 3.0, 2.8, 1.2, 0.9, and 0.6 for G1 to G5. The Baxter parameters were 0.257 (b1), 0.065 (b2), and 0.0002 (b3), as used by Kadokawa et al. (2003).

Data were analyzed by using Statview (ver. 5.0 for Macintosh; SAS Inst., Inc., Cary, NC) and JMP (ver. 4.0.5 for Windows; SAS Inst., Inc.). For plasma concentrations of FFA, insulin, IGF-I, and leptin, significance of the effect of time was evaluated by repeated measures ANOVA. No significant effect of time was observed for FFA, IGF-I, or leptin, so mean concentrations for each cow were calculated for the sampling period and used for further analysis. For insulin, a consistent increase in concentrations occurred as sampling progressed (time effect; $P<0.05$ ), so mean values were calculated for each cow for the sampling period, and used for further analysis.

The Shapiro-Wilk's W test or Kolmogrov-Smirnov Lilliefors test were used to evaluate the normality or lognormality of distribution of each variable. Most variables were normally distributed, but LH pulse amplitude, mean LH concentration, GH pulse amplitude, milk protein content, and mean FFA concentration had log-normal distributions, for which logarithmic values were used. There were no outliers in any variables (Grubb's test).

Pearson correlation coefficients were estimated among the measures of $\mathrm{LH}$ secretion and other variables.

\section{RESULTS}

On d 14, cows required $70.4 \pm 3.0 \mathrm{Mcal} / \mathrm{d}$ of $\mathrm{ME}$, but were able to consume only $47.0 \pm 3.3 \mathrm{Mcal} / \mathrm{d}$. All 18 cows were in negative energy balance $(-23.4 \pm 2.4 \mathrm{Mcal} /$ d). Wide differences existed among cows for each metabolic variable measured, as evidenced in the minima and maxima listed in Table 1. Similarly, wide variation existed among cows in measures of pulsatile LH secretion.

Table 2 shows the correlation coefficients for the postulated relationships between variables that describe LH pulse profiles, plasma concentrations of leptin, and other measures of metabolic status. The most important significant relationships also are displayed (Figure 1). A strong positive correlation was detected between LH pulse frequency and energy balance (Figure 1a) and between LH pulse frequency and circulating leptin concentrations (Figure 1b). Milk fat content (Figure 1c) was correlated negatively with LH pulse frequency. Logarithm of LH pulse amplitude was correlated only 
Table 1. Body condition, milk production, and plasma concentrations of FFA, leptin, insulin, insulin-like growth factor-I (IGF-I), growth hormone (GH), and LH in dairy cows on d 14 postpartum

\begin{tabular}{lccccccc}
\hline & Mean & SE & Minimum & Maximum & CV, \% & Kurtosis & Skewness \\
\hline Energy balance, Mcal/d & -23.4 & 2.4 & -37.6 & -8.3 & 43.1 & -1.45 & 0.06 \\
BCS & 3.0 & 0.1 & 2.5 & 3.5 & 13.3 & -1.29 & -0.06 \\
Daily milk yield, kg & 40.7 & 1.8 & 20.4 & 51.4 & 18.4 & 0.96 & -0.86 \\
Milk fat, \% & 4.24 & 0.17 & 3.18 & 6.07 & 16.7 & 0.66 & 0.94 \\
Milk protein, \% & 3.10 & 0.14 & 2.09 & 4.76 & 18.4 & $1.29^{1}$ & $0.33^{1}$ \\
FFA, nEq/mL & 544.0 & 88.0 & 137.0 & $1,689.0$ & 69.0 & $-0.57^{1}$ & $0.19^{1}$ \\
Leptin, ng/mL & 0.73 & 0.03 & 0.54 & 1.12 & 19.5 & 1.27 & 1.16 \\
Insulin, mU/L & 5.79 & 0.81 & 1.19 & 12.33 & 59.4 & -0.92 & 0.49 \\
IGF-I, ng/mL & 18.90 & 2.41 & 6.40 & 45.44 & 53.7 & 0.77 & 1.05 \\
GH pulses per 8 h & 3.2 & 0.3 & 1.0 & 5.0 & 36.3 & -0.41 & -0.33 \\
GH pulse amplitude, ng/mL & 3.81 & 0.65 & 1.84 & 13.22 & 73.0 & $1.21^{1}$ & $1.38^{1}$ \\
GH, ng/mL & 4.49 & 0.44 & 0.25 & 4.20 & 25.0 & -0.58 & 0.22 \\
LH pulses per 8 h & 3.7 & 0.4 & 0.0 & 7.0 & 51.4 & -0.35 & 0.12 \\
LH pulse amplitude, ng/mL & 0.97 & 0.11 & 0.54 & 2.28 & 47.4 & $0.77^{1}$ & $1.06^{1}$ \\
LH, ng/mL & 0.84 & 0.09 & 0.43 & 2.15 & 46.4 & $0.67^{1}$ & $0.50^{1}$ \\
\hline
\end{tabular}

${ }^{1}$ Logarithm was used for calculating kurtosis and skewness.

with leptin values (Figure 1d). Frequency of GH pulses was not correlated with LH pulse measures (Table 2), but was correlated negatively with plasma concentrations of insulin (Figure 1f) and IGF-I (Figure 1g). Mean GH concentration also was not correlated with $\mathrm{LH}$ pulse measures and was negatively correlated only with plasma IGF-I concentrations (Figure 1h). Notably, the relationship between leptin concentrations and energy balance was poor $(P<0.10)$, but leptin concentrations correlated negatively with milk fat content (Figure 1e).

The largest follicle observed in both ovaries of each cow on $\mathrm{d} 14 \mathrm{had}$ a diameter of $12.1 \pm 0.3 \mathrm{~mm}$, and no cystic follicles of diameter $>20 \mathrm{~mm}$ were detected. First ovulation was observed on $34 \pm 4 \mathrm{~d}$ (range 18 to $65 \mathrm{~d}$ ) after parturition.

\section{DISCUSSION}

In early postpartum Holstein cows during the period of negative energy balance before first ovulation, plasma concentrations of leptin were demonstrated to be strongly correlated with the frequency and amplitude of LH pulses. Pulse frequency is controlled by the hypothalamus through the frequency of $\mathrm{GnRH}$ pulses, and pulse amplitude is controlled primarily by pituitary responsiveness to $\mathrm{GnRH}$, so these relationships support the role that has been hypothesized for leptin as a link between metabolic status and activity of the neuroendocrine system that controls reproductive status (Kadokawa et al., 2000) Mean LH concentrations were not correlated with leptin concentrations, but average values of high-amplitude, pulsatile secretion are a very imprecise and insensitive measure of GnRH activity. Leptin receptor mRNA is expressed in both the hypothalamus and anterior pituitary gland, at least in the rat (Zamorano et al., 1997). Hypothalamic receptors for leptin are located in regions that are rich in GnRH neurons, such as the arcuate nucleus, medial preoptic area, and median eminence in ruminants (Dyer et al.,

Table 2. Correlations between measures of secretion of LH, energy balance, BCS, milk production and quality, and plasma concentrations of FFA, leptin, insulin, insulin-like growth factor-I (IGF-I), and measures of growth hormone (GH) secretion in dairy cows on d 14 postpartum

\begin{tabular}{|c|c|c|c|c|c|c|c|c|}
\hline & $\begin{array}{l}\text { LH } \\
\text { pulses }\end{array}$ & $\begin{array}{l}\text { LH pulse } \\
\text { amplitude }^{1}\end{array}$ & $\mathrm{LH}^{1,2}$ & $\begin{array}{l}\text { GH } \\
\text { pulses }\end{array}$ & $\begin{array}{l}\text { GH pulse } \\
\text { amplitude }^{1}\end{array}$ & $\mathrm{GH}^{2}$ & Leptin $^{2}$ & $\mathrm{FFA}^{1,2}$ \\
\hline Energy balance & $0.514^{*}$ & 0.203 & 0.100 & -0.463 & -0.040 & -0.128 & 0.414 & $-0.626^{* *}$ \\
\hline $\mathrm{BCS}$ & -0.273 & 0.167 & 0.440 & -0.162 & -0.276 & -0.255 & -0.106 & 0.313 \\
\hline Milk fat & $-0.518^{*}$ & -0.159 & -0.019 & -0.283 & 0.134 & 0.157 & $-0.517 *$ & 0.720 *** \\
\hline Milk protein ${ }^{1}$ & -0.100 & -0.266 & 0.081 & -0.063 & -0.047 & 0.067 & -0.409 & 0.096 \\
\hline $\mathrm{FFA}^{1,2}$ & -0.461 & -0.135 & 0.032 & $0.485^{*}$ & 0.025 & 0.185 & -0.248 & - \\
\hline GH pulses & -0.027 & 0.204 & 0.085 & - & -0.027 & 0.454 & -0.019 & $0.485^{*}$ \\
\hline GH pulse amplitude ${ }^{1}$ & 0.016 & 0.225 & -0.033 & -0.027 & - & $0.755^{* * *}$ & -0.039 & 0.025 \\
\hline $\mathrm{GH}^{2}$ & 0.065 & 0.374 & 0.068 & 0.454 & $0.755^{* * *}$ & - & -0.099 & 0.185 \\
\hline
\end{tabular}

${ }^{1}$ Logarithmically transformed data were used for analysis of correlation.

${ }^{2}$ Concentration.

$* P<0.05 ; * * P<0.01 ; * * * P<0.001$. 
(a)

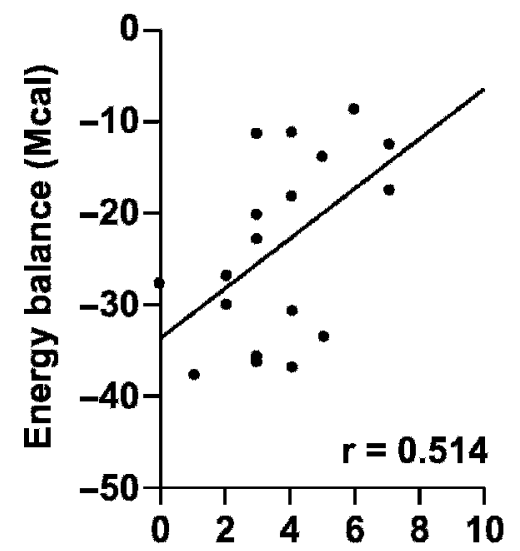

LH pulse frequency

(d) (b)

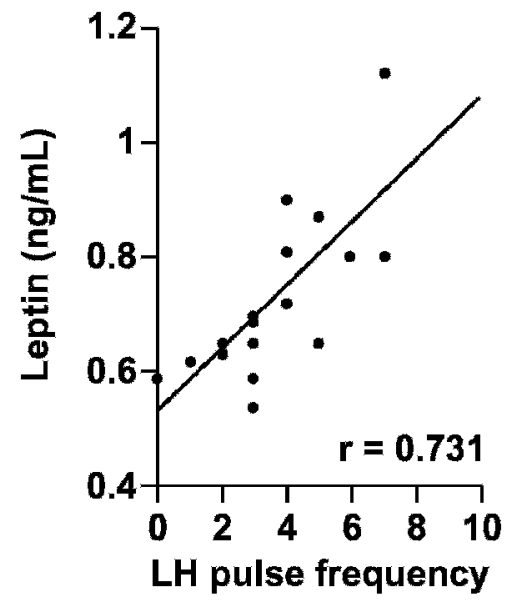

(c)

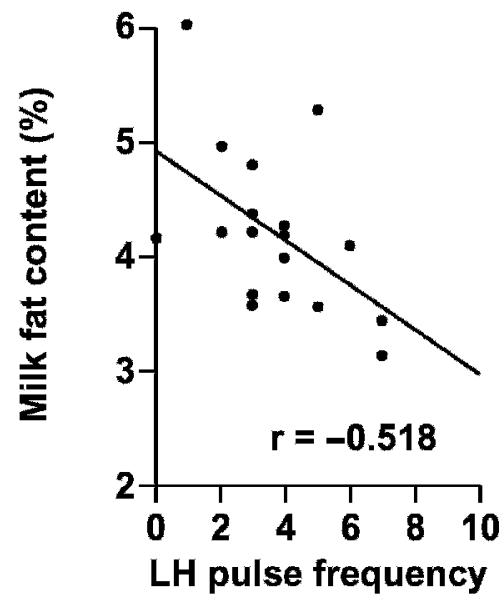

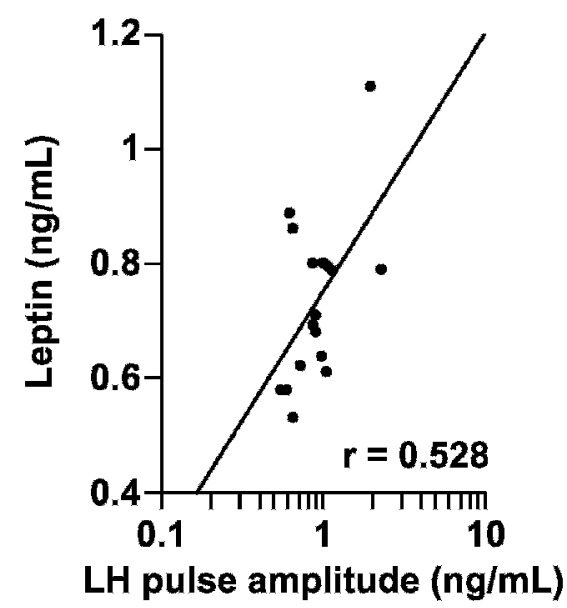

(f)

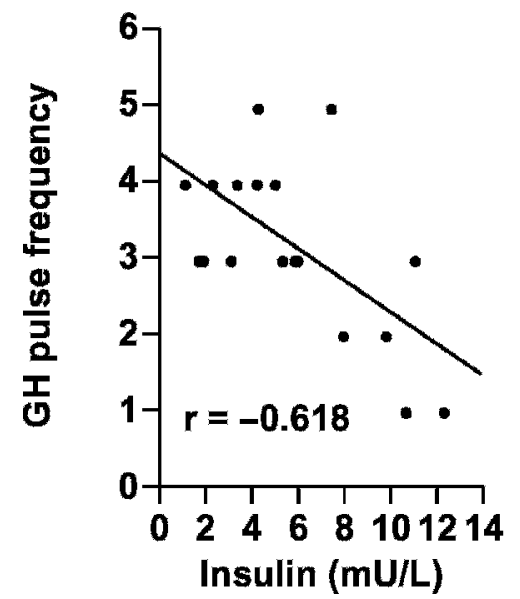

(g)

(e)

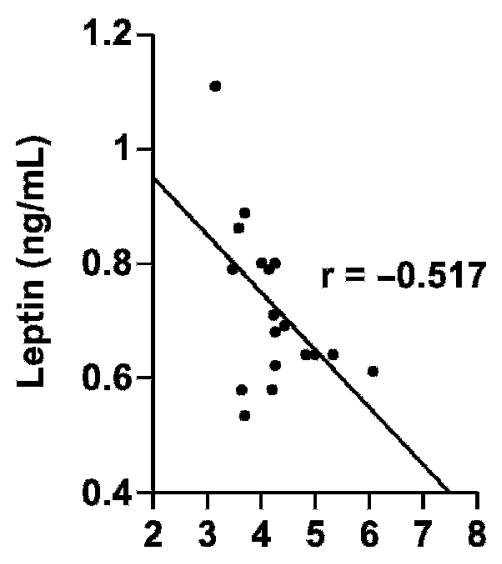

Milk fat content (\%)

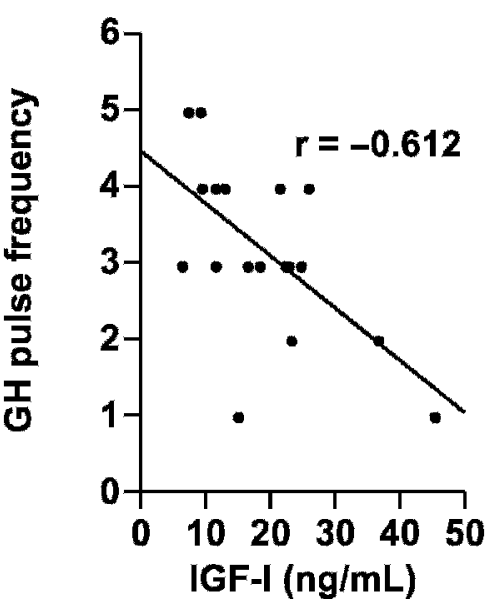

(h)

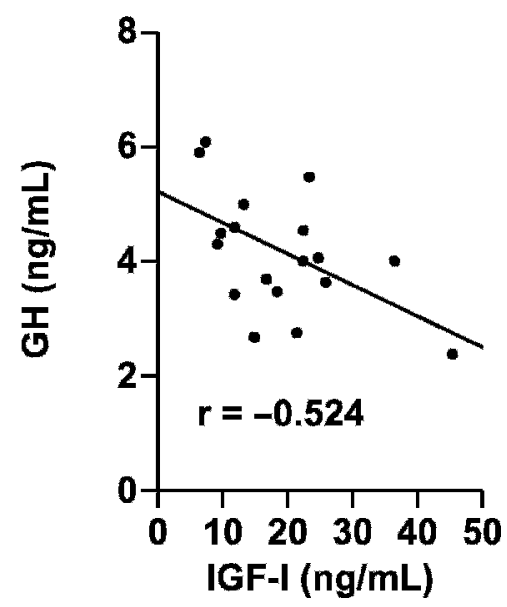

Figure 1. Metabolic and endocrine relationships in d 14 postpartum dairy cows under negative energy balance: relationships between the frequency of pulses of LH and (a) energy balance, (b) plasma concentrations of leptin, and (c) milk fat content; relationships between plasma concentrations of leptin and (d) LH pulse amplitude, and (e) milk fat content; relationships between the frequency of pulses of growth hormone $(\mathrm{GH})$ and (f) plasma concentration of insulin, and (g) plasma concentration of insulin-like growth factor-I (IGF-I), and (h) between plasma concentrations of IGF-I and GH. 
1997). In rodents, leptin binding in the arcuate nucleus is increased during fasting (Baskin et al., 1999), and fasting for $48 \mathrm{~h}$ on d 13 and 14 postpartum prolonged lactational anestrus, a response that is eliminated by central or peripheral administration of leptin (Abizaid et al., 2004). In ruminants, less information is available, but leptin seems to be responsible for changes in $\mathrm{LH}$ secretion in animals that are suffering severe energy shortage.

Leptin is clearly not the only endocrine factor that can contribute to delays in postpartum ovulation. In particular, IGF-I needs to be considered because circulating concentrations in the peripartum period are a good predictor of the capacity of energy-restricted cows to resume cyclicity (Roberts et al., 1997). Cows with ovulatory estrogen-active follicles have greater IGF-I concentrations during the first 2 wk than cows with anovulatory follicles (Beam and Butler, 1998). Both insulin and IGF-I can stimulate steroidogenesis and proliferation of bovine theca and granulosa cells (Spicer and Stewart, 1996). On the other hand, elevated concentrations of leptin (10 to $300 \mathrm{ng} / \mathrm{mL}$ ) can both increase the insulin-induced proliferation of thecal cells and inhibit steroidogenesis in bovine ovarian tissues (Spicer et al., 2000). Thus, it seems likely that leptin and IGFI interact in controlling the resumption of ovulation in postpartum dairy cows, but further studies are required to determine the roles played by lesser concentrations of leptin at the ovarian level.

Postpartum dairy cows mobilize body fat while their energy balance is negative (Tamminga et al., 1997), and this was reflected in the increases in FFA concentrations and milk fat content in the present study. When energy balance is negative, leptin secretion by the adipocytes is likely to be reduced, as is seen with fasting or underfeeding (Henry et al., 2001). Frequency of LH pulses also was correlated with milk fat content, but not with plasma FFA values. In sheep, infusion of FFA inhibits pulsatile secretion of GH, but not LH (Estienne et al., 1990). We also have seen no effect of i.v. infusion of FFA on the secretion of $\mathrm{LH}$ pulses in postpartum cows (H. Kadokawa, unpublished data). Thus, the increase in plasma FFA probably does not directly affect GnRHLH secretion and simply accompanies the reduction in leptin secretion. Despite the indirect nature of this link to the potential for ovulation, the measurement of milk fat content is easy and inexpensive and therefore may be a useful tool for the management of reproduction in postpartum dairy cows.

Body condition score was not correlated with the frequency or amplitude of LH pulses. Three possible reasons may account for this observation. First, the error inherent in BCS values is larger than that in blood metabolite analyses because of the subjectivity and im- precision of BCS measurements. Second, postpartum dairy cows also rely on protein mobilization from skeletal muscle (Tamminga et al., 1997) and this would affect BCS. Third, BCS might not be an accurate index of the total mass of adipocytes that secrete leptin or of acute changes in secretory activity of those cells. In our previous study of changes in leptin secretion around parturition in dairy cows (Kadokawa et al., 2000), BCS was still elevated when leptin concentrations began to decrease several days before parturition, and were still reduced when leptin concentrations began to increase before the postpartum first ovulation. Meikle et al. (2004) reported that plasma leptin content was a good indicator of body fatness in prepartum dairy cows, especially $3 \mathrm{wk}$ before calving, a stage when leptin is highly expressed. On the other hand, Holtenius et al. (2003) found no relationship between leptin concentrations and BCS after parturition.

It is therefore clear that changes in leptin concentrations are not simply related to changes in BCS; other factors that control leptin secretion need to be considered. Among these, energy balance is likely to be important because it strongly affects the correlation between adipocyte size and leptin secretion in humans (Houseknecht et al., 1998). In rats, Abizaid et al. (2004) reported that circulating leptin concentrations decreased during lactation and showed that eliminating energetic costs of lactation by preventing milk delivery dramatically increased plasma leptin concentrations and adiposity. In cows that are not milked after parturition, plasma concentrations of leptin remain elevated, so in this species as well a postpartum reduction in leptin secretion is likely to be, at least partially, caused by negative energy balance (Block et al., 2001). On the other hand, in the early lactation cows studied by Kokkonen et al. (2005), plasma leptin concentration was associated with body fatness but not with estimated energy balance. Another consideration is the physiological preparation for lactation, as suggested by Chelikani et al. (2004), who reported that fasting induced a sharper reduction of plasma leptin concentrations in cows in early lactation than in nonlactating pregnant Holsteins. Overall, it seems likely that the decreased secretion of leptin after parturition is a consequence of combined effects of changes in energy balance, body condition, and physiological changes needed to prepare for lactation.

Lack of correlation between frequencies of $\mathrm{GH}$ pulses and LH pulses shows that independent mechanisms control responses of these 2 systems to changes in energy balance. Frequency of GH pulses was inversely related to the plasma concentrations of insulin and IGFI. Inability of GH to stimulate hepatic IGF-I production during periods of negative energy balance, labeled " $\mathrm{GH}$ - 
resistance" (Donaghy and Baxter, 1996), can be reversed by the administration of insulin in experimental models using the hyperinsulinemic-euglycemic clamp (Butler et al., 2003). Therefore, reduced concentrations of IGF-I that we observed might have been caused by reduced concentrations of insulin. From this correlation study we cannot determine the precise mechanism involved, but there may be reduced negative feedback by IGF-I on the activity of the hypothalamo-pituitary system that controls GH secretion. This feedback has been reported mainly for monogastrics (Veldhuis et al., 2004), and little is known in ruminants, but it does seem to exist in postpartum dairy cows (Butler et al., 2003). Its effectiveness may depend on other aspects of the hormonal environment. For example, in nonlactating ewes fed a maintenance ration, intracerebroventricular infusion of IGF-I has no effect on GH pulse measures, whereas intrapituitary infusion reduces GH concentrations without affecting GH pulse frequency (Fletcher et al., 1995). Thus, a circulating factor(s) seems to contribute to the negative feedback effect of IGF-I in lactating dairy cows. Our study suggests that insulin might be that factor.

\section{CONCLUSIONS}

These results reveal an important link between secretion of leptin and LH in early postpartum dairy cows, both of which are limiting during fat mobilization from adipose tissues under negative energy balance. This linkage might help explain the delay to first ovulation postpartum.

\section{ACKNOWLEDGMENTS}

We are grateful to the personnel of National Agricultural Research Centre for Hokkaido Region, especially Y. Jou, for technical assistance. Thanks are also extended to A. F. Parlow of National Institute of Diabetes and Digestive and Kidney Diseases for supplying the antihuman IGF-I antiserum, the bLH and anti-oLHantiserum, bGH, and anti-bGH-antiserum. This study was supported in part by a grant-in-aid (Biological Resource Management for Sustainable Agricultural Systems) from the Organization for Economic Co-operation and Development, and a grant-in-aid (Bio Design Program) from the Ministry of Agriculture, Forestry and Fisheries, Japan. Development of the leptin assay was supported by the National Health and Medical Research Council of Australia (grant no. 981672).

\section{REFERENCES}

Abizaid, A., D. Kyriazis, and B. Woodside. 2004. Effects of leptin administration on lactational infertility in food-restricted rats depend on milk delivery. Am. J. Physiol. 286:R217-R225.
Agriculture, Forestry and Fisheries Research Council Secretariat. 1999. Japanese Feeding Standard for Dairy Cattle. Central Association of Livestock Industry, Tokyo, Japan.

Baskin, D. G., J. F. Breininger, S. Bonigut, and M. A. Miller. 1999. Leptin binding in the arcuate nucleus is increased during fasting. Brain Res. 828:154-158.

Beam, S. W., and W. R. Butler. 1998. Energy balance, metabolic hormones, and early postpartum follicular development in dairy cows fed prilled lipid. J. Dairy Sci. 81:121-131.

Blache, D., R. L. Tellam, L. M. Chagas, M. A. Blackberry, P. E. Vercoe, and G. B. Martin. 2000. Level of nutrition affects leptin concentrations in plasma and cerebrospinal fluid in sheep. J. Endocrinol. 165:625-637.

Block, S. S., W. R. Butler, R. A. Ehrhardt, A. W. Bell, M. E. Van Amburg, and Y. R. Boisclair. 2001. Decreased concentration of plasma leptin in periparturient dairy cows is caused by negative energy balance. J. Endocrinol. 171:341-350.

Butler, S. T., A. L. Marr, S. H. Pelton, R. P. Radcliff, M. C. Lucy, and W. R. Butler. 2003. Insulin restores GH responsiveness during lactation-induced negative energy balance in dairy cattle: Effects on expression of IGF-I and GH receptor 1A. J. Endocrinol. 176:205-217.

Canfield, R. W., and W. R. Butler. 1991. Energy balance, first ovulation and the effects of naloxone on LH secretion in early postpartum dairy cows. J. Anim. Sci. 69:740-746.

Chelikani, P. K., J. D. Ambrose, D. H. Keisler, and J. J. Kennelly. 2004. Effect of short-term fasting on plasma concentrations of leptin and other hormones and metabolites in dairy cattle. Domest. Anim. Endocrinol. 26:33-48.

Donaghy, A. J., and R. C. Baxter. 1996. Insulin-like growth factor bioactivity and its modification in growth hormone resistant states. Baillieres Clin. Endocrinol. Metab. 10:421-426.

Dyer, C. J., J. M. Simmons, R. L. Matteri, and D. H. Keisler. 1997. Leptin receptor mRNA is expressed in ewe anterior pituitary and adipose tissues and is differentially expressed in hypothalamic regions of well-fed and feed-restricted ewes. Domest. Anim. Endocrinol. 14:119-128.

Edmonson, A. J., I. J. Lean, L. D. Weaver, T. Farver, and G. Webster. 1989. A body condition scoring chart for Holstein dairy cows. J. Dairy Sci. 72:68-78.

Estienne, M. J., K. K. Schillo, S. M. Hileman, M. A. Green, S. H. Hayes, and J. A. Boling. 1990. Effects of free fatty acids on luteinizing hormone and growth hormone secretion in ovariectomized lambs. Endocrinology 126:1934-1940.

Fletcher, T. P., G. B. Thomas, F. R. Dunshea, L. G. Moore, and I. J. Clarke. 1995. IGF feedback effects on growth hormone secretion in ewes: Evidence for action at the pituitary but not the hypothalamic level. J. Endocrinol. 144:323-331.

Henry, B. A., J. W. Goding, A. J. Tilbrook, F. R. Dunshea, and I. J. Clarke. 2001. Intracerebroventricular infusion of leptin elevates the secretion of luteinizing hormone without affecting food intake in long-term food-restricted sheep, but increases growth hormone irrespective of bodyweight. J. Endocrinol. 168:67-77.

Holtenius, K., S. Agenas, C. Delavaud, and Y. Chilliard. 2003. Effects of feeding intensity during the dry period. 2. Metabolic and hormonal responses. J. Dairy Sci. 86:883-891.

Houseknecht, K. L., C. A. Baile, R. L. Matteri, and M. E. Spurlock. 1998. The biology of leptin: A review. J. Anim. Sci. 76:1405-1420.

Kadokawa, H., D. Blache, Y. Yamada, and G. B. Martin. 2000. Relationships between changes in plasma concentrations of leptin before and after parturition and the timing of first post-partum ovulation in high-producing Holstein dairy cows. Reprod. Fertil. Dev. 12:405-411.

Kadokawa, H., J. R. Briegel, M. A. Blackberry, D. Blache, G. B. Martin, and N. R. Adams. 2003. Relationships between plasma concentrations of leptin and other metabolic hormones in GHtransgenic sheep infused with glucose. Domest. Anim. Endocrinol. 24:219-229.

Kokkonen, T., J. Taponen, T. Anttila, L. Syrjala-Qvist, C. Delavaud, Y. Chilliard, M. Tuori, and A. T. Tesfa. 2005. Effect of body fatness and glucogenic supplement on lipid and protein mobilization and plasma leptin in dairy cows. J. Dairy Sci. 88:1127-1141. 
Liefers, S. C., R. F. Veerkamp, M. F. W. Te Pas, Y. Chilliard, and T. Van der Lende. 2005. Genetics and physiology of leptin in periparturient dairy cows. Domest. Anim. Endocrinol. 29:227238.

Meikle, A., M. Kulcsar, Y. Chilliard, H. Febel, C. Delavaud, D. Cavestany, and P. Chilibroste. 2004. Effects of parity and body condition at parturition on endocrine and reproductive parameters of the cow. Reproduction 127:727-737.

Merriam, G. R., and K. W. Watcher. 1982. Algorithms for the study of episodic hormone secretion. Am. J. Physiol. 243:E310-E318.

Roberts, A. J., R. A. Nugent, J. Klindt, and T. G. Jenkins. 1997. Circulating insulin-like growth factor 1 , insulin-like growth factor binding proteins, growth hormone, and resumption of oestrus in postpartum cows subjected to dietary energy restriction. J. Anim. Sci. 75:1909-1917.

Spicer, L. J., C. S. Chamberlain, and C. C. Francisco. 2000. Ovarian action of leptin: Effects on insulin-like growth factor-I-stimulated function of granulosa and thecal cells. Endocrine 12:53-59.
Spicer, L. J., and R. E. Stewart. 1996. Interactions among basic fibroblast growth factor, epidermal growth factor, insulin, and insulin-like growth factor-I (IGF-I) on cell numbers and steroidogenesis of bovine thecal cells: Role of IGF-I receptors. Biol. Reprod. $54: 255-263$

Tamminga, S., P. A. Luteijn, and R. G. M. Meijer. 1997. Changes in composition and energy content of liveweight loss in dairy cows with time after parturition. Livest. Prod. Sci. 52:31-38.

Veldhuis, J. D., J. Y. Weltman, A. L. Weltman, A. Iranmanesh, E. E. Muller, and C. Y. Bowers. 2004. Age and secretagogue type jointly determine dynamic growth hormone responses to exogenous insulin-like growth factor-negative feedback in healthy men. J. Clin. Endocrinol. Metab. 89:5542-5548.

Zamorano, P. L., V. B. Mahesh, L. M. DeSevilla, L. P. Chorich, G. K. Bhat, and D. Brann. 1997. Expression and localization of the leptin receptor in endocrine and neuroendocrine tissues of the rat. Neuroendocrinology 65:223-228.

Zurek, E., G. R. Foxcroft, and J. J. Kennelly. 1995. Metabolic status and interval to first ovulation in postpartum dairy cows. J. Dairy Sci. 78:1909-1920. 